\title{
Oberflächen schonend trocknen und reinigen
}

\author{
Das synchrone Trocknen und Reinigen von Oberflächen ist integrierter Bestandteil vieler \\ industrieller Prozesse. Vor allem wenn diese Aufgaben berührungslos ausgeführt werden sollen, \\ bewährt sich der Einsatz eines pneumatischen Luft-Vorhangs. Das Pneumatik-Modul lässt sich \\ zudem einfach in vorhandene Anlagen und Produktionslinien integrieren.
}

Der Einsatzbereich von Luftklingen für die berührungslose Trocknung oder Reinigung von Oberflächen und Werkstücken ist breit gefächert. So findet man dieses Pneumatik-Modul beispielsweise unter anderem in Sterilisationsprozessen und in Lackieranlagen. In den meisten Fällen geht es dabei darum, Oberflächen und Bauteile schonend und ohne Kontakt zu Mensch und Maschine abzukühlen, zu trocknen und gleichzeitig von Staubund Schmutzpartikeln sowie Flüssigkeitsresten zu befreien. Weitere Einsatzgebiete dieser Luftklingen (Typ Line-Blow von Kager) sind die gezielte Verwirbelung und

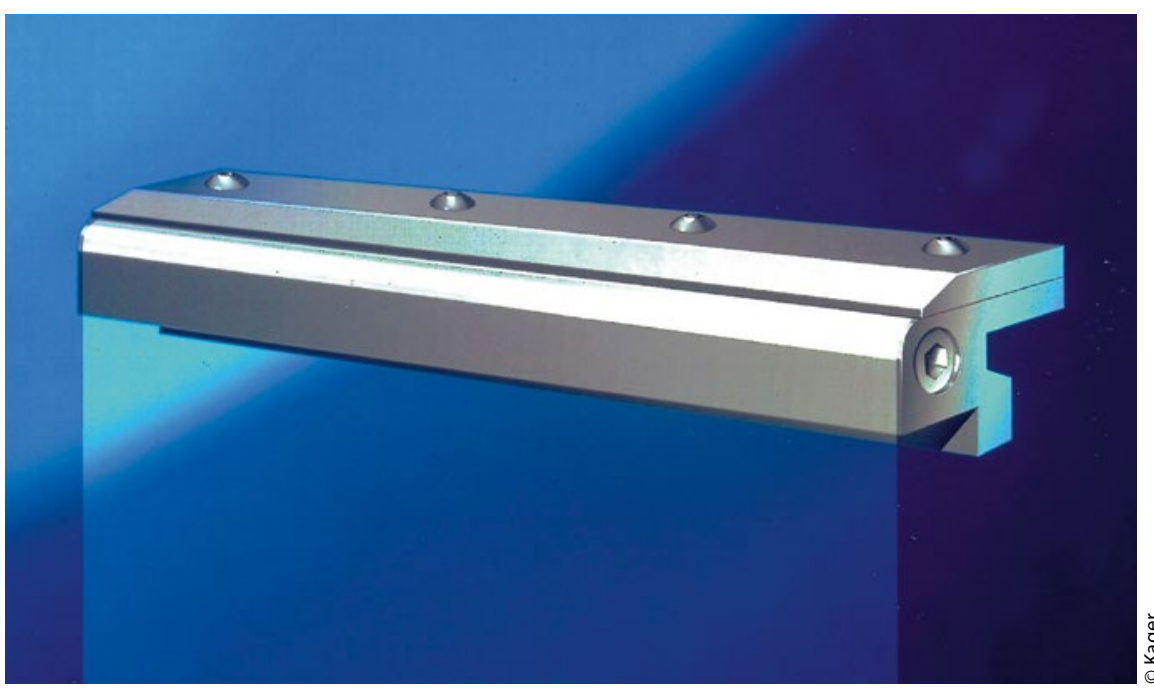

Mit Hilfe einer pneumatischen Luftklinge lassen sich Oberflächen und Bauteile schonend und berührungslos abkühlen, trocknen und von Staub- und Schmutzpartikeln sowie Flüssigkeitsresten befreien.
Verteilung luftgängiger Medien oder auch die Trennung von Objekten unterschiedlichen Gewichts.

\section{Wand aus kühler Luft}

Die Luftklinge erzeugt - je nach Modellvariante - über Breiten von 150 bis 900 Millimeter eine dünne Gardine beziehungsweise Wand aus kühler, trockener Luft. Entsprechend der Einbausituation und Anwendung lässt sich das Pneumatik-Modul hängend, liegend oder stehend einbauen. Es wird über einen $1 / 4$-Zoll-Anschluss an das betriebliche Druckluftnetz ange- schlossen und arbeitet sehr geräuscharm. Dank seiner kompakten Bauform lässt sich der Luft-Vorhang auch einfach in bestehende Kühl-, Trocknungs- und Reinigungslinien integrieren.

Kager bietet den Line-Blow in zwei Gehäusetypen an. Für viele industrielle Prozesse ist die leichte Standardausführung aus Aluminium die bevorzugte Variante. Die Alternative ist eine korrosionsbeständige Edelstahl-Ausführung. Für längere Förder- oder Durchlaufstrecken können auch mehrere Line-Blows zu Stafetten in Reihe geschaltet werden.

\section{Zielgenau und effizient}

Der geometrisch präzise Luft-Vorhang entsteht durch das spezielle Design des Gehäuses beziehungsweise der LuftaustrittsÖffnung. Durch einen nur 50 Mikrometer dünnen Spalt erhält der ausgestoßene Luftstrom seine flächige Ausdehnung und wird zielgenau in die beabsichtigte Richtung gelenkt. Dabei ist das Luftvolumen der erzeugten Luftgardine 25-mal höher als die zugeführte Druckluft. //

\section{Kontakt}

Kager Industrieprodukte GmbH

Dietzenbach

Tel. 06074400930

info@kager.de

www.kager.de 